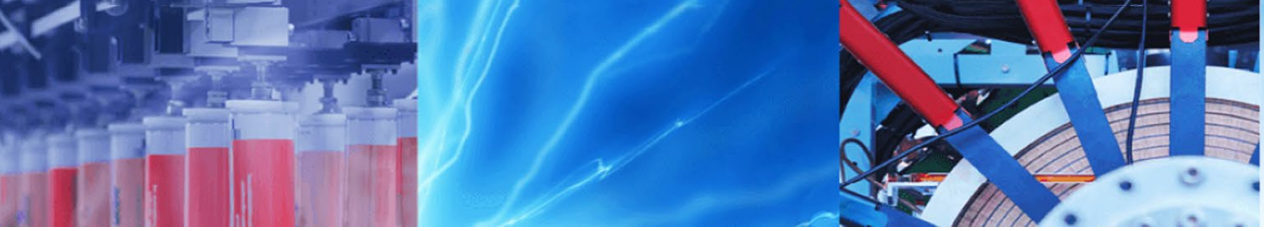

Research Article

\title{
Development and performance evaluation of a Pedal Operated Seed Cleaner (POS-Cleaner)
}

\author{
Wilber Akatuhurira ${ }^{1} \cdot$ Peter Tumutegyereize ${ }^{1}$ (D) Isaac Oluk ${ }^{2} \cdot$ Emmanuel Baidhe $^{1}$. Julia Kigozi ${ }^{1}$. Ismael Mayanja ${ }^{3}$. \\ Hussein Balimunsi Kivumbi ${ }^{1}$
}

Received: 29 September 2020 / Accepted: 28 April 2021

Published online: 30 May 2021

(c) The Author(s) $2021 \quad$ OPEN

\begin{abstract}
Traditional grain cleaning methods are labor-intensive, time-consuming, and yet very inefficient. The use of available mechanical seed cleaners is widely limited since they are expensive to own, operate, and maintain. A Pedal Operated Seed Cleaner (PoS-Cleaner) was developed and its performance evaluated. Appropriate engineering principles and methodologies were used in the sizing and construction of the machine. The cleaner consists of a bicycle-like pedaling system, hopper, a centrifugal fan, and three cleaning sieves which include two inside interlocking sieves (one sieve fixed and the other adjustable); whose meshes can be adjusted to be larger than the size of the unclean seeds by longitudinally translating the second sieve to achieve the appropriate seed size. This allows trapping of impurities larger than the seeds. Cleaning rates of $576.5 \mathrm{~kg} / \mathrm{h}, 375.8 \mathrm{~kg} / \mathrm{h}$, and $377.4 \mathrm{~kg} / \mathrm{h}$ for maize, beans, and groundnuts were obtained respectively. Maize, beans, and groundnuts had their highest cleaning efficiencies of $95.09 \%, 87.61 \%$, and $81.67 \%$ at inner sieve sizes of $13 \mathrm{~mm}, 16 \mathrm{~mm}$ and $10 \mathrm{~mm}$ respectively, pedaling speed of $60 \mathrm{rpm}$. The PoS-Cleaner presents a more viable cleaning option for smallholder farmers in rural and remote areas with no access to the national grid, therefore producing highquality seeds. This will eventually facilitate agricultural value addition and increase individual family incomes in Uganda.
\end{abstract}

\section{Article highlights}

- A pedal operated multi-seed cleaner was developed.

- Achieved 5 times higher seed cleaning rates compared to traditional cleaning technologies.
- Attained higher separation efficiencies of seed and externalities compared to traditional technologies.

Keywords Pedal Operated Seed Cleaner $\cdot$ Smallholder farmers $\cdot$ Cleaning rates $\cdot$ Cleaning efficiencies $\cdot$ Uganda

$\triangle$ Peter Tumutegyereize, pierretumutegye@gmail.com; Wilber Akatuhurira, akatuhurirawilber@gmail.com; Isaac Oluk, oluk@ badayetechnologies.com; Emmanuel Baidhe, ebaidhe@gmail.com; Julia Kigozi, ibulyakigozi@yahoo.com; Ismael Mayanja, ikmayanja@ ucdavis.edu; Hussein Balimunsi Kivumbi, balimunsi@caes.mak.ac.ug| ${ }^{1}$ Department of Agricultural and Biosystems Engineering, Makerere University, P.O. Box 7062, Kampala, Uganda. ${ }^{2}$ Badaye Technologies Ltd, P.O Box 4932, Kampala, Uganda. ${ }^{3}$ Department of Biological and Agricultural Engineering, University of California, Davis, One Shields Avenue, Davis, CA 95616, USA.

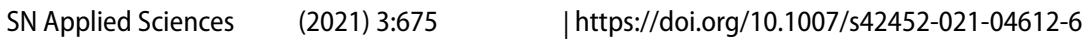




\section{Introduction}

Grains constitute the greatest portion of daily diets for many populations worldwide [1]. They are a major source of carbohydrates, but also provide proteins, fiber, as well as micronutrients such as vitamins and minerals $[2,3]$. Uganda produces both cereal and legume grains. By acreage, the latest agricultural census conducted in 2008/2009 revealed that cereals cover the largest area of cultivated land in Uganda with over 1.7 million ha while pulses cover close to 980 thousand ha of land $[4,5]$. However, post-harvest losses continue to be a major challenge in Uganda. According to FAO, WFP and IFAD [6], critical losses at the household level, an average of $67 \mathrm{~kg}$ of beans and $590 \mathrm{~kg}$ for maize are lost per year leading to an annual financial loss of US\$ 14.5 and US\$110 respectively. The Ministry of Agriculture, Animal Industry, and Fisheries (MAAIF) also partially attributes food insecurity in Uganda to poor post-harvesting handling [7]. Postharvest losses due to quality losses remains one of the most neglected paths through which grains are lost. The ultimate quality of the finished product, storage stability, organoleptic properties, safety from health hazards, and consumer acceptance depends on the cleaning process.

Cleaning is one of the important post-harvest steps that aids storage, processing, quality control, and pest management. However, grain cleaning is mainly done using rudimentary manual methods. For instance, majority farmers in Uganda have continued to use their conventional cleaning techniques such as winnowing trays and screens for cleaning maize even with huge maize yields. Not only do these methods contribute to poor post-harvest handling, but they are also tedious, laborintensive, time-consuming [8]. Manual cleaning methods are also characterized by low capacity, high inconsistencies, and low cleaning efficiency since they depend on human perception [9]. Therefore, cleaning operations could best be improved with the use of mechanical cleaning equipment. However, the available imported cleaners are energy demanding, complex to repair, and expensive in terms of ownership, operation, and maintenance. Also, the locally-manufactured grain cleaners, though relatively cheap, are often designed for cleaning a single type of seeds. For instance, the Pedal Operated Maize cleaner (PoM-Cleaner) which was developed in 2018 had an efficiency of $83.1 \%$ with Longe $1 \mathrm{H}$ maize variety [8]. This, therefore, excludes other maize varieties as well as other grains that need to be cleaned before selling them.

Therefore, there is a need for a single-multipurpose grain cleaning system to alleviate the bottlenecks for grain cleaning among smallholder farmers. This study aimed to develop a novel Pedal-Operated Seed (PoSCleaner) cleaning technology that will facilitate cleaning a variety of seeds, increasing efficiency of seed cleaning, and consequently reducing post-harvest losses. With this technology, farmers will use the saved time to attend to other economic activities. The PoS-Cleaner will enable farmers in rural and remote areas that have no access to the national grid to equally produce high-quality seeds, therefore facilitating agricultural value addition. This may also increase the individual family incomes. The use of PoS-Cleaner may provide a viable cleaning option for smallholder farmers, who contribute over $80 \%$ of the country's farming population [10]. This may eventually increase their productivity to match the medium and large-scale farmers.

The structure of this article is as follows: Sect. 1 is the introduction explaining the need and the rationale of the study. Materials and methods for the design, development and performance evaluation as well as the strategy for upscaling and adoption are presented in Sect. 2 . Section 3 presents the results and discussion in relation to the existing literature while Sect. 4 is on conclusions.

\section{Materials and methods}

\subsection{Machine description}

The PoS-Cleaner (Fig. 1) is an adapted and upgraded design of the pedal-operated maize grain cleaner [8]; developed to clean not only maize but also all other seeds of size diameter $6.6-18 \mathrm{~mm}$. The PoS-Cleaner is tailored to significantly remove foreign materials such as chaff, stones, dust, and other crops from the desired seeds. The cleaner consists of a bicycle-like pedaling system, hopper, a centrifugal fan, and three cleaning sieves. The three sieves consist of the outer fixed sieve and the two inside interlocking sieves that can be adjusted depending on the size of grains to be cleaned.

During operation, the unclean seeds are fed into the hopper which then flows down gravitationally. At this stage, light foreign materials are blown off by the centrifugal fan. This first separation stage utilizes the difference in aerodynamic property of the materials being separated. After, the seeds are channeled to the rotary sieves for further separation. The fan and sieve rotary motion derived from pedaling supports seed continuous movement through the sieves due to gravity and centrifugal forces. Clean seeds are then collected in one receptacle through the seed outlet. 


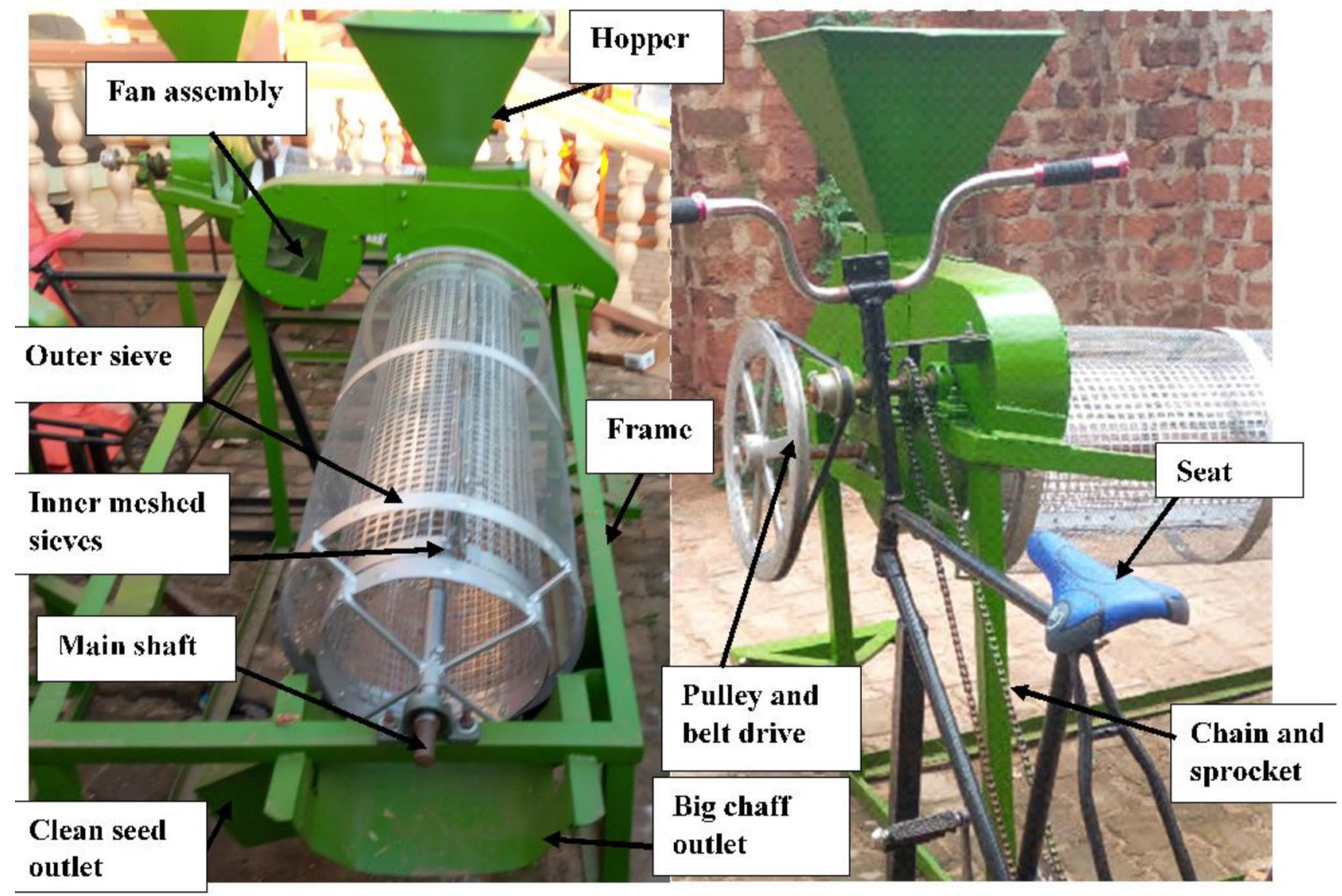

Fig. 1 Assembly of the Pedal Operated Seed Cleaner

\subsection{Design of the pedal-operated seed cleaner components}

\subsubsection{Hopper}

The hopper shape is of a square-base pyramid frustum. The volume of the hopper was determined using Eq. (1) Hopper capacity for the different grains was determined using Eq. (2) [8].

$V=\frac{h}{3}\left(A_{1}+A_{2}+\sqrt{ }\left(A_{1} \times A_{2}\right)\right)$

$M=\rho \times V$

where $\mathrm{V}$ is the volume of a hopper $\left(\mathrm{m}^{3}\right), \mathrm{h}$ is the height of the hopper ( $\mathrm{m}), A_{1}$ is the area of the top part of a hopper $\left(\mathrm{m}^{2}\right), A_{2}$ is the area of the bottom part of the hopper $\left(\mathrm{m}^{2}\right)$ and $\rho$ is the density of the grain.

\subsubsection{Trommels (Rotating sieves)}

Figure 2 shows the three sieves that rotate in tandem whereby two inner sieves are meshed together and can

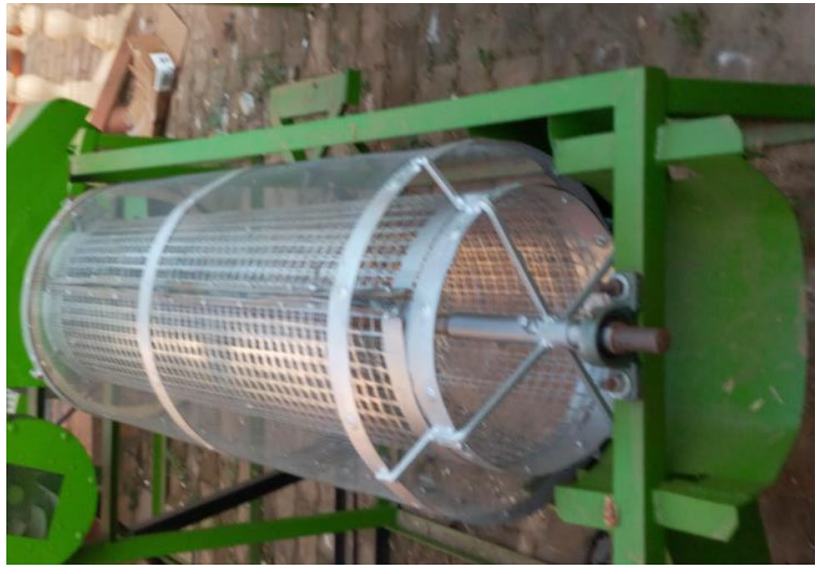

Fig. 2 Sieves rotating in tandem

be adjusted longitudinally to vary the mesh hole size. This flexibility of adjusting the mesh hole sizes allows grains of varying sizes to be cleaned. To ensure higher cleaning efficiency from the trommels (rotary sieves) length, diameter, speed, and angle of inclination were the major parameters considered $[11,12]$. The desired operating speed of 
trommels was computed relative to the critical speed, the speed at which a centripetal acceleration of $9.8 \mathrm{~m} / \mathrm{s}^{2}$ at the screen surface is achieved [13]. According to Mayanja, Kigozi, Kawongolo and Brumm [8], the best operating speed of the rotating sieve ranges from 33 to $45 \%$ of the critical speed. Critical speed $\left(\mathrm{N}_{\mathrm{c}}\right)$ was determined from the sieve radius using the relationship in Eq. (3) [13].

$N_{C}=\frac{30}{\pi} \sqrt{\frac{g}{R \sin \theta}}$

where $N_{c}$ is the critical angular speed of the sieve (rpm); $R$ is the radius of the sieve $(\mathrm{m}) ; \mathrm{g}$ is the acceleration due to gravity $\left(\mathrm{m} / \mathrm{s}^{2}\right) ; \theta$ is the maximum angle of lifting approximated to be the angle of friction (degrees).

\subsubsection{Belt and pulley design}

The Pedal Operated Seed Cleaner has two pulleys with a belt connection to transmit power from the chain drive to the trommels (Fig. 3). The diameter of the pulley is given by the relationship in Eq. (4) while the length of the belt (L) depends on the diameter of the driven and driving pulleys and the center distance between the pulleys given by the relationship in Eq. (5). Center distance (C) between two adjacent pulleys $(\mathrm{m})$ was determined by Eq. (6) [15]. Tension in the tight side of the belt $\left(T_{1}\right)$ is created on that

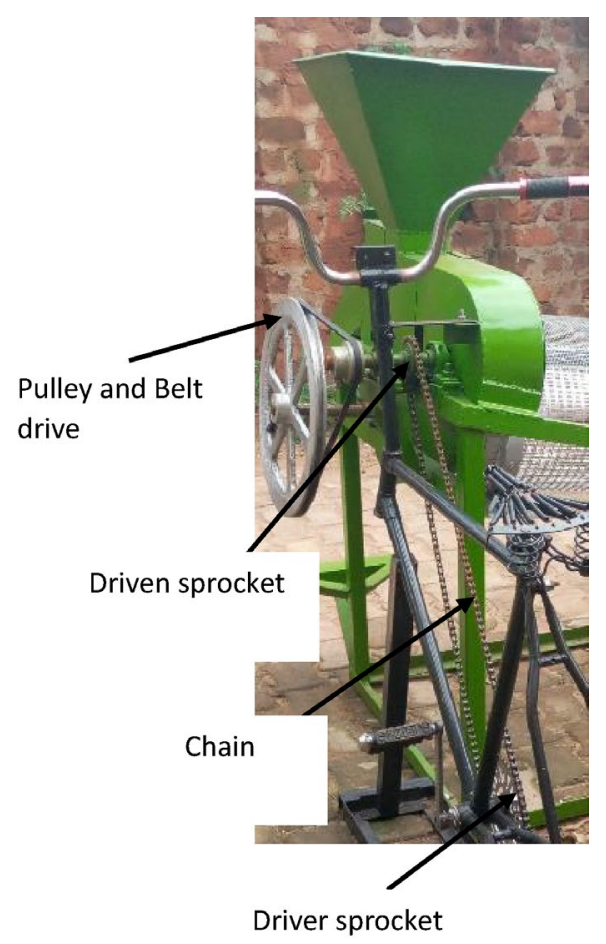

section of the belt approaching the driver pulley. Tight side tension is a function of both maximum tension and centrifugal tension. Tight side tension is given by Eq. (7). Slack side tension is created on the section of the belt approaching the driven pulley. The slack side tension $\left(T_{2}\right)$ of the belt is given by Eq. (8). The power required in transmitting the belt $\left(P_{1}\right)$ was determined using Eq. (9). Equations to determine the other parameters defined in here can always be found in Khurmi and Gupta [14].

$\frac{d_{1}}{d_{2}}=\frac{N_{2}}{N_{1}}$

$L=2 C+1.57\left(d_{1}+d_{2}\right)+\frac{\left(d_{2}-d_{1}\right)^{2}}{4 C}$

$C=\frac{d_{1}+d_{2}}{2}+d_{1}$

$\mathrm{T}_{1}=\mathrm{T}_{\text {max }}-\mathrm{T}_{\mathrm{c}}$

$2.3 \log \left(\frac{T_{1}}{T_{2}}\right)=\mu \emptyset \csc \beta$

$P_{1}=\left(T_{1}-T_{2}\right) v$

where $d_{1}$ is the diameter of the driver pulley $(m), d_{2}$ is the diameter of the driven pulley $(m), N_{1}$ is the speed of the driver pulley (rpm), $\mathrm{N}_{2}$ is the speed of the driven pulley (rpm) and $\mathrm{C}$ is the center distance between two adjacent pulleys $(m) T_{\text {max }}$ is the maximum allowable tension in the belt $(N), T_{c}$ is the centrifugal tension in the belt, $\beta$ is the half groove angle (degrees), $\varnothing$ is the angle of lap on the smaller pulley (radians), $\mu$ is the angle of friction between the belt and the pulley (unitless), $v$ is the speed of the belt $(\mathrm{m} / \mathrm{s})$.

\subsubsection{Sprockets and chain drive design}

The driver and driven sprockets are connected through a chain as shown in Fig. 3. The driven sprocket (small) runs at the same speed as the driver pulley in the belt-pulley arrangement. The driver sprocket (Big) runs at a speed determined by the relationship given by Eq. (10). The length of the chain $\left(L_{c}\right)$ was determined using Eq. (11) The power transmitted by the chain $\left(\mathrm{P}_{2}\right)$ based on breaking load was determined using Eq. (12). Equations to determine the other parameters defined in here can always be found in Khurmi and Gupta [14].

$\mathrm{N}_{\mathrm{s}} \mathrm{T}_{\mathrm{s}}=\mathrm{N}_{\mathrm{b}} \mathrm{T}_{\mathrm{b}}$

$L_{c}=K p$

Fig. 3 The drive mechanism 
$P_{2}=\frac{W_{b} \times v_{c}}{n \times k_{s}}$

where $\mathrm{N}_{\mathrm{s}}$ is the speed of rotation for the small sprocket (rpm), $N_{b}$ is the speed of rotation for the big pulley (rpm), $T_{s}$ is the number of teeth for the small sprocket, $T_{b}$ is the number of teeth for the big sprocket, $\mathrm{K}$ is the number of chain links, $p$ is the pitch of the chain, $C_{c}$ is the center distance between the sprockets $(\mathrm{mm}), \mathrm{W}_{\mathrm{b}}$ is the breaking load (N), $n$ is the factor of safety, $v_{c}$ is the velocity of the chain, and $\mathrm{k}_{\mathrm{s}}$ is the service factor.

\subsubsection{Power required to operate the machine}

The total power required to run the machine was calculated by summing the power required in transmitting the belt and the chain given by Eq. (13).

$P=P_{1}+P_{2}$

\subsubsection{Design of Sieve shaft}

The diameter of the shafts was ascertained mathematically using Eq. (14). The angle of twist was used to establish if the shaft was safe. The angle of twist was determined using Eq. (15) according to Olusegun et al. [16]. Equations to determine the other parameters defined in here can always be found in Mayanja et al. [8].

$D^{3}=\frac{16}{\pi \tau_{s}} \sqrt{\left(K_{B} M_{B}\right)^{2}+\left(K_{T} M_{T}\right)^{2}}$

$\theta=\frac{584 M_{T} \mathrm{~L}}{G D^{4}}$

where $D$ is the diameter of the shaft $(m), K_{B}$ is the combined shock and fatigue factor applied to bending moment, $\mathrm{K}_{\mathrm{T}}$ is the combined shock and fatigue factor applied to torsional moment, $\tau_{s}$ is the allowable shear stress for bending and torsion $\left(\mathrm{N} / \mathrm{m}^{2}\right), M_{B}$ is the maximum bending moment $(\mathrm{Nm}), \mathrm{M}_{\mathrm{T}}$ is the torsional moment $(\mathrm{Nm}) \theta$ is the angle of twist (degrees), $\mathrm{M}_{\mathrm{T}}$ is the torsional moment $(\mathrm{Nm}), \mathrm{G}$ is the torsional modulus of rigidity $\left(\mathrm{N} / \mathrm{m}^{2}\right), \mathrm{L}$ is the length of the shaft $(\mathrm{m})$.

\subsubsection{Design of centrifugal blower}

A blower is used to move the air constantly with a slight increase in static pressure to allow for separation of the grain-chaff mixture. The blower air discharge was estimated using the expression of continuity as given by Eq. (16) [16].

$\mathrm{Q}=A_{4} \mathrm{~V}$ where $Q$ is the air discharge $\left(\mathrm{m}^{3} / \mathrm{s}\right), A_{4}$ is the area of the blade $\left(\mathrm{m}^{2}\right)$ and $V$ is the velocity of air $(\mathrm{m} / \mathrm{s})$ produced form the blower.

\subsection{Performance evaluation of the PoS Cleaner machine}

The performance of the machine was evaluated using maize, beans, and groundnuts as they are the most commonly grown grains in Uganda. Mixtures of known weights of maize, beans, and groundnuts and undesirable materials (Table 1) were fed into the machine. During the operation of the machine, the clean grains were collected at the clean seed outlet while undesired material was collected at the chaff outlet. Parameters including Separation loss $(\mathrm{SL})$, separation efficiency (SE), cleaning loss $(\mathrm{CL})$, cleaning efficiency (CE), cleaning rate (CR), seed damage (SD), and total cleaning efficiency (TCE) were used to establish the performance of the PoS Cleaner.

The weight of the undesired material to be mixed with grains was determined in triplicate using a well-calibrated digital weighing scale. Samples for the three grains (maize, beans, and groundnuts) were prepared in three replicates. The three weighed grain samples were then thoroughly mixed with known quantities of the undesired material. A single batch of grain-undesired materials mixture was then fed into the machine for cleaning. A stopwatch was immediately started. At the end of the run, the stopwatch was stopped and the time taken to clean the sample was recorded. The material collected at the clean seed outlet was sorted into the clean grain and the undesired material. The weight of the clean grain and undesired material collected at the clean seed outlet was then determined using a digital weighing scale. The process was repeated for all the prepared samples.

\subsubsection{Separation loss (SL) and separation efficiency (SE)}

The separation loss (SL) was determined as the proportion of the total weight of material other than desired seeds collected at the clean seed outlet to the total weight of undesired material fed into the machine as given by Eq. (17). Separation efficiency explains the extent to which impurities are effectively removed from the mixture.

Table 1 Proportions of gain and undesired material used in performance evaluation

\begin{tabular}{|c|c|c|c|}
\hline Grain materials & Maize & Beans & Groundnuts \\
\hline Mass of grain $(\mathrm{kg})$ & 10 & 10 & 10 \\
\hline $\begin{array}{l}\text { Mass of undesired } \\
\text { material }(\mathrm{kg})\end{array}$ & 0.608 & 1.635 & 0.627 \\
\hline
\end{tabular}


Separation efficiency is defined as the ratio of the amount of undesired material separated in the cleaning system to the amount of undesired material to be separated fed into the cleaning system. Separation efficiency (SE) is given by Eq. (18) [17].

$S L=\left(\frac{W_{2}}{W_{1}}\right) \times 100$

$\mathrm{SE}=\left(\frac{W_{1}-W_{2}}{W_{1}}\right) \times 100$

where $W_{1}$ is the weight of undesired material mixed with clean seed before cleaning $(\mathrm{kg})$ and $W_{2}$ is the weight of undesired material that is collected at the clean seed outlet after cleaning $(\mathrm{kg})$.

\subsubsection{Cleaning loss (CL) and cleaning efficiency (CE)}

Cleaning loss determined the amount of grain left behind with the machine. Cleaning loss is the ratio of the weight of grain lost during the process of cleaning to the weight of grain fed into the machine as shown in Eq. (19). Cleaning efficiency is the measure of the extent to which gains are separated from the mixture. The cleaning efficiency was determined using Eq. (20) [17].

$C L=\left(\frac{W_{3}-W_{4}}{W_{3}}\right) \times 100$

$C E=\left(\frac{W_{4}}{W_{3}}\right) \times 100$

where $W_{3}$ is the weight of clean seeds mixed with undesired material before cleaning $(\mathrm{kg})$ and $\mathrm{W}_{4}$ is the weight of clean seeds collected at the clean seed outlet after cleaning $(\mathrm{kg})$.

\subsubsection{Cleaning rate (CR)}

Using a stopwatch, the time taken to clean $10 \mathrm{~kg}$ of the grain was taken and recorded. The experiment was done in three replications for each of the grain samples. The cleaning rate for the machine was determined using Eq. (21). In addition, data was collected from farmers whom the cleaners had been distributed to regarding quantities of produce cleaned and time taken. This data was used to plot a graph from which the actual cleaning rate was approximate.

$\mathrm{CR}=\left(\frac{3600 W_{3}}{T}\right) \times 100$

where $\mathrm{T}$ is the time taken to clean a sample (s).

\subsubsection{Seed damage (SD)}

This determines the extent to which seeds are damaged in the process of cleaning. A $1 \mathrm{~kg}$ sample of grain was weighed and fed to the cleaning machine. The cleaning was then done and the grain collected at the outlet was sorted into whole and damaged seeds. The weight of damaged seeds was taken using a digital weighing scale. The experiment was done in three replications. Seed damage (SD) was determined as the proportion of the weight of damaged seeds after cleaning to the total seeds fed into the machine as given by Eq. (22) [18].

$\mathrm{SD}=\frac{\mathrm{W}_{\mathrm{D}}}{\mathrm{W}_{\mathrm{T}}} \times 100$

where $W_{D}$ is the weight of grain damaged after cleaning $(\mathrm{kg}), W_{\mathrm{T}}$ is the weight of grains fed into the machine $(\mathrm{kg})$.

\subsubsection{Total cleaning efficiency (TCE)}

The total cleaning efficiency is the product of the efficiency of recovery of desired seeds and the efficiency of separation of undesired material given by Eq. (23) [19].

$\mathrm{TCE}=\frac{\mathrm{SE} \times \mathrm{CE}}{100}$

\subsubsection{Optimization of the cleaning process}

The geometric mean diameter was used to estimate the grain size. A sample of 25 grains was picked from maize, beans, and groundnut batches. Using a vernier caliper, the grain dimensions (length, width, and thickness) were measured and used to calculate the geometric mean diameter for maize, beans, and groundnuts using Eq. (24) [20].

Size $=(a \times b \times c)^{\frac{1}{3}}$

where $a$ is the length ( $\mathrm{mm}) ; b$ is the width $(\mathrm{mm}) ; \mathrm{c}$ is the thickness $(\mathrm{mm})$ of the grain.

The inner sieve was then adjusted based on the size of grains. Ten kilograms of maize were mixture with known volumes of undesirable material. The inner sieve was adjusted to $12 \mathrm{~mm}$ and the mixture was then fed into the cleaning machine after which pedaling was done at $60 \mathrm{rpm}$. This is because lower cadences are known for lower energy demands [21]. The weight of clean maize collected at the clean seed outlet was determined using a digital weighing scale. The experiment was done in duplicate and an average was taken. The same procedure was repeated when the inner sieve was set at 13, 14, and $15 \mathrm{~mm}$ respectively. The respective cleaning efficiencies were determined using Eq. (20). The process was repeated 
for beans with inner sieve holes adjusted to $14,15,16$, and $17 \mathrm{~mm}$ and for ground nuts with inner sieve holes adjusted to $8,10,12,14,16 \mathrm{~mm}$. The values of cleaning efficiency were compared to establish the highest values. The sieve hole size at which the cleaning machine recorded the highest cleaning efficiency was taken to be the optimal sieve hole size for the grain while pedaling at $60 \mathrm{rpm}$.

\subsection{Strategy for upscaling and adoption}

To ensure upscaling and adoption of the seed-Cleaner, the project team was composed of a community-based NGO that works with farmers, academia and a local manufacturing company. This partnership has enabled continued production of the machines by the manufacturing company as the NGO continues to promote the machines among the farmers.

\section{Results and discussion}

\subsection{Design of PoS-Cleaner components}

Considering a hopper of the base side of $0.1 \mathrm{~m}$ and a top side of $0.4 \mathrm{~m}$ and a height of $0.31 \mathrm{~m}$, the volume of the hopper was determined using Eq. (1) as $0.0217 \mathrm{~m}^{3}$. With the density of maize, beans, and groundnuts at $720 \mathrm{~kg} / \mathrm{m}^{3}$ [8], $1145 \mathrm{~kg} / \mathrm{m}^{3}$ [22], and $752 \mathrm{~kg} / \mathrm{m}^{3}$ [23] respectively, the hopper capacity was found using Eq. (2) as $15.6 \mathrm{~kg}, 24.8 \mathrm{~kg}$, and $16.3 \mathrm{~kg}$ for maize, beans, and groundnuts respectively.

Considering the coefficient of friction of 0.805 for maize, 1.407 , beans (approximated to the coefficient of friction for soybean) [24] and 0.76 for groundnuts [25], the highest value of 1.407 was used for calculation of the angle of friction. The critical speed for the inners and outer sieves was calculated using Eq. (3) and found to be $82.8 \mathrm{rpm}$ and 69.8 rpm respectively.

Considering the operating speed of the rotating sieve to be $33 \%$ of the critical speed for the inner sieves, the rotary speed for the driver pulley was calculated using Eq. (4) as $138.5 \mathrm{rpm}$. Using Eq. (6) the center distance between pulleys was calculated as $0.343 \mathrm{~m}$. The length of the belt was calculated using Eq. (5) as $1.63 \mathrm{~m}$. Considering the use of Type A V-belt with a groove angle of $34^{\circ}$ since the system requires low power, the cross-sectional area of the belt was calculated using Eq. (11) as $4.2 \times 10^{-4}$ $\mathrm{m}^{2}$. Using maximum permissible stress for the rubber of $2.5 \mathrm{MPa}$ [14], the maximum allowable tension in the belt was calculated using Eq. (8) as $1050 \mathrm{~N}$. The speed of the belt was calculated using Eq. (10) as $0.55 \mathrm{~m} / \mathrm{s}$. Centrifugal tension in the belt was calculated using Eq. (9) as $0.145 \mathrm{~N}$. The tension on the tight side of the belt was calculated using Eq. (7) as 1049.9 N. Using Eq. (13), the angle of lap on the smaller pulley was calculated as $1.96 \mathrm{rad}$. Using a coefficient of friction of 0.3 for rubber-cast iron surface [14], the tension on the slack side of the belt was calculated using Eq. (12) as $140.2 \mathrm{~N}$. The power transmitted by the belt was calculated using Eq. (14) as $500.3 \mathrm{~W}$ (0.67 hp).

For a set of bicycle chain system with a small sprocket of 20 teeth, a big sprocket of 46 teeth, and chain pitch of grade $08 \mathrm{~B}$ (approximately $12.7 \mathrm{~mm}$ ), the speed of rotation for the big sprocket was calculated using Eq. (15) as $60.2 \mathrm{rpm}$. The minimum center distance between the small and big sprockets was taken to be 40 times the pitch according to Khurmi and Gupta [14]. The value of minimum center distance was reduced by 4 making the correct center distance $504 \mathrm{~mm}$. The number of chain links was calculated using Eq. (17) as 113. The length of the chain was determined using Eq. (16) as $1432.56 \mathrm{~mm}$. The velocity of the chain was calculated using Eq. (19) as $0.58 \mathrm{~m} / \mathrm{s}$. Using Eq. (20), the service factor was calculated as 1.875 . Using a breaking load of $17.8 \mathrm{kN}$ and factor of safety of 22.2 , the power transmitted by the chain was calculated using Eq. (18) as $248.02 \mathrm{~W}$ (0.33 hp). The overall power required to run the cleaning machine was determined using Eq. (21) as $1 \mathrm{hp}$.

Using the bending moment of $25.58 \mathrm{~N} / \mathrm{m}$ and torsional moment of $207.7 \mathrm{~N} / \mathrm{m}$, shaft diameter was calculated using Eq. (22) as $0.034 \mathrm{~m}$. A standard shaft size of $25 \mathrm{~mm}$ was selected for the purpose. With a torsional modulus of rigidity of $84 \mathrm{GPa}$ for steel [14], the angle of twist for the shaft was calculated using Eq. (15) as 6.1 degrees. The air discharge for the blower was calculated using Eq. (16) as $0.432 \mathrm{~m}^{3} / \mathrm{s}$.

\subsection{Construction of the machine}

The construction of the PoS Cleaner was done at the production workshop of Badaye Technologies Limited located in Kawaala, Kampala City, Uganda using well-detailed production drawings. The construction started with the purchase of requisite materials upon a proper assessment of the designs. The materials were purchased from the local market. Operations such as marking out, cutting of metal pieces, bending, welding, drilling, grinding, assembly, and painting were done during construction.

The frame was fabricated using mild steel (MS) with angle lines of $40 \times 40 \times 4 \mathrm{~mm}$ and square hollow sections of $40 \times 40 \times 3 \mathrm{~mm}$. The hopper, fan, and fan housing were fabricated using mild steel sheets $(1.2 \mathrm{~mm}$ thick). Mild steel was selected because of its high durability strength, affordability and it is the most available metallic material in the local market. Aluminum sheets $(6.5 \mathrm{~mm}$ thick) were used for the development of the two-inner sieves using the Computer Numerical Control (CNC) machining technologies. The pedal system was adopted from the bicycle 
frame design (Roadmaster Bicycle Frame) with a saddle and chainring which assured stability and comfortability.

\subsection{Performance evaluation}

\subsubsection{Separation loss (SL) and separation efficiency (SE)}

Generally, SL was relatively low for cereal grains compared to legume grains. The SE was however higher for cereals compared to the legume grains as shown in Table 2. The SL for the PoS-Cleaner was found to be $4.55 \%, 11.44 \%$, and $16.91 \%$ for maize, beans, and groundnuts respectively. The SE was found to be $95.45 \%, 88.56 \%, 83.09 \%$ for maize, beans, and groundnuts respectively. This indicates that the PoS-Cleaner separates undesired material more effectively from the mixture with maize grains compared to the beans and groundnuts. From Mayanja et al. [8] design, 8\% separation loss for maize was obtained indicating that this PoSCleaner is better.

\subsubsection{Cleaning loss (CL) and cleaning efficiency (CE)}

The $\mathrm{CL}$ was low while $\mathrm{CE}$ was higher for all grains as depicted in Table 2. The CL was found to be $0.383 \%$, $1.087 \%$, and $1.73 \%$ for maize, beans, and groundnuts respectively. The CE was $99.62 \%, 98.92 \%$, and $98.3 \%$ for maize, beans, and groundnuts respectively. These efficiencies are much higher than the $87 \%$ registered by Mayanja et al. [8]. This indicates that the machine has a higher ability to separate grains from the undesired material for both cereal and legume grains.

\subsubsection{Cleaning rate (CR)}

The $\mathrm{CR}$ rate for maize, beans, and groundnuts was found to be $576.5 \mathrm{~kg} / \mathrm{h}, 375.8 \mathrm{~kg} / \mathrm{h}$, and $377.4 \mathrm{~kg} / \mathrm{h}$ respectively (Table 2). The CR is slightly higher for maize compared to beans and groundnuts. Beans and groundnuts have almost similar CR. This could be attributed to grains shape similarities that exist between bean and groundnuts. This means that the same machine can effectively clean more maize grains than beans and groundnuts for the same cleaning period. In addition, data collected from farmers whom the cleaners were distributed to, reveals a cleaning rate of $516 \mathrm{~kg} / \mathrm{h}$ as shown in Fig. 4. This cleaning rate is not far from that achieved under specified conditions. These rates are 3-5 times higher than the rate reported by MAAIF [26] for an individual when using the conventional cleaning methods. However, when compared with what Mayanja et al. [8] developed, the rate of cleaning falls short by $146 \mathrm{~kg}$. This probably is due to the three separating sieves in this cleaner causing seeds to take a longer time before coming out compared to one sieve that is in Mayanja et al. [8] cleaner.

\subsubsection{Total cleaning efficiency (TCE)}

From Table 2, the TCE was relatively higher for maize with $95.08 \%$ followed by beans and groundnuts at $87.61 \%$ and $81.68 \%$ respectively. This is attributed to the higher values of CE and SE for maize compared to beans and groundnuts. The higher values for maize indicate that the machine can effectively separate undesired materials from the maize grain compared to bean and groundnuts.

\subsubsection{Seed damage (SD)}

Seed vigor and viability are critical characteristics for the germination of any seed [27]. Vigor and viability are greatly affected by seed damage. Mechanical cleaning

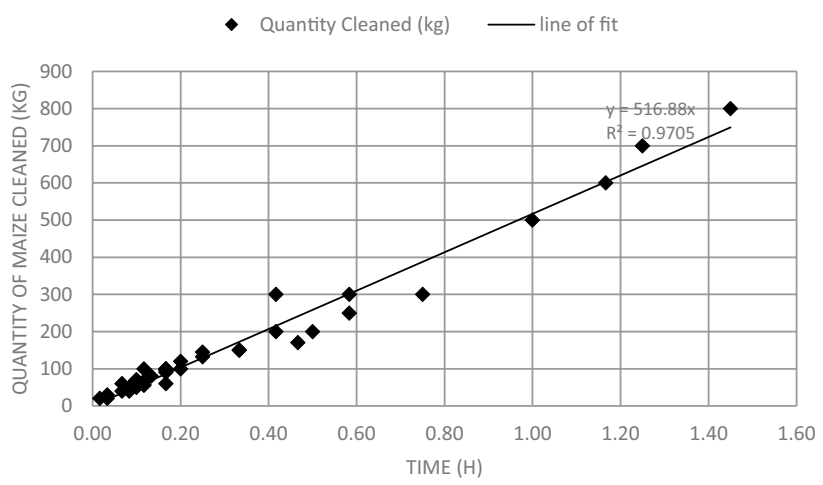

Fig. 4 Quantities of maize cleaned with respect to time taken by different farmers

Table 2 Results for the parameters for the different grains

\begin{tabular}{llllllll}
\hline Grain & \multicolumn{1}{l}{ SL (\%) } & SE (\%) & CL (\%) & CE (\%) & CR (kg/h) & TCE (\%) & SD (\%) \\
\hline Maize & $4.55 \pm 0.191$ & $95.45 \pm 0.191$ & $0.383 \pm 0.047$ & $99.62 \pm 0.047$ & $576.5 \pm 41.92$ & $95.08 \pm 0.146$ & $0.33 \pm 0.058$ \\
Beans & $11.44 \pm 0.582$ & $88.56 \pm 0.582$ & $1.087 \pm 0.045$ & $98.92 \pm 0.045$ & $375.8 \pm 21.5$ & $87.61 \pm 0.592$ & 0.00 \\
Groundnut & $16.91 \pm 1.416$ & $83.09 \pm 1.146$ & $1.73 \pm 0.557$ & $98.30 \pm 0.539$ & $377.4 \pm 36.09$ & $81.68 \pm 0.954$ & $0.87 \pm 0.153$
\end{tabular}

$S L$ separation loss, SE separation efficiency, $C L$ cleaning loss, $C E$ cleaning efficiency, $C R$ cleaning rate, $T C E$ total cleaning efficiency, SD seed damage 
Fig. 5 A plot of cleaning efficiency against sieve size

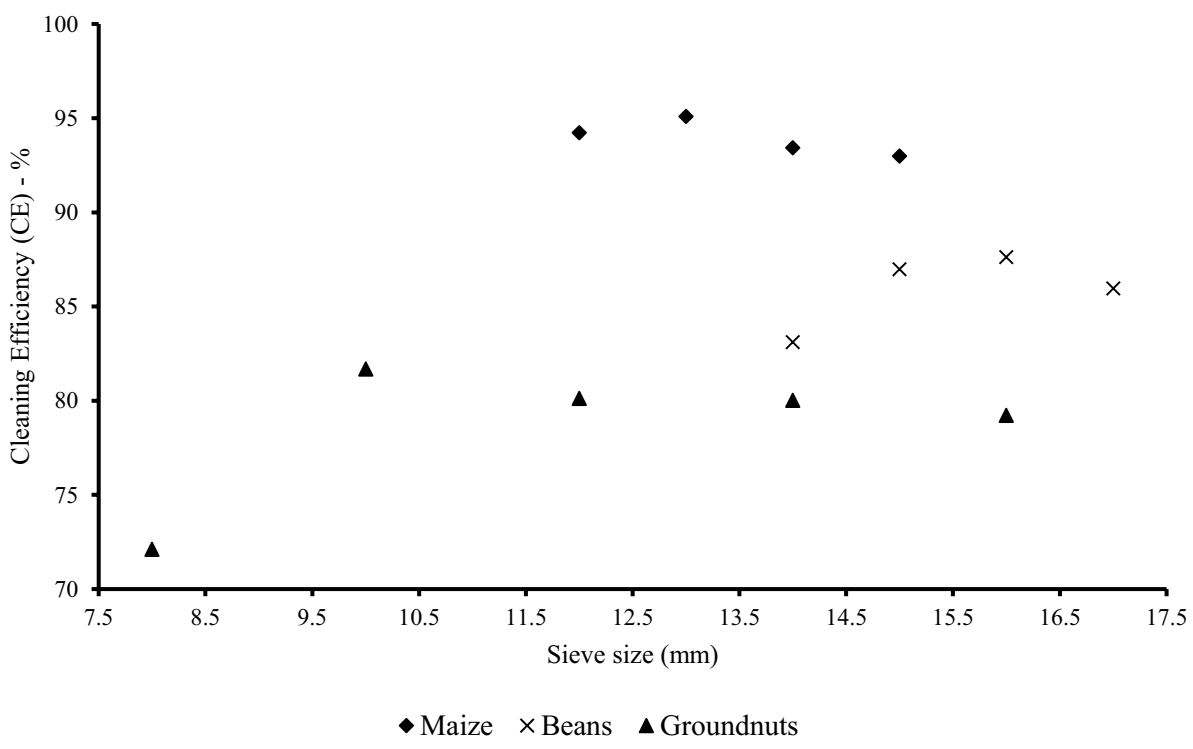

leads to damage of seeds and reduces their quality. The results indicate that SD for all grains is less than $1 \%$ for all grains as compared to the $2 \%$ obtained by Mayanja et al. [8] (Table 2). This substantiates that the machine can effectively be used for cleaning planting material as it guarantees seed quality in terms of vigor and viability.

\subsubsection{Optimization of the cleaning process}

Figure 5 shows the variation of cleaning efficiency with sieve size. It is observed that the cleaning efficiency is initially low but increases with increasing sieve size for all grains. The low CE at smaller sieve sizes is attributed to the inability of the grains to fall through the sieve, therefore ending up in the chaff. At a very large sieve size, the CE is observed to reduce for all grains. This could be a result of excessive infiltration of the undesired materials into the grains, which is eventually collected at the clean grain outlet. Upon optimizing the sieve size for the different grains, results indicate that maize, beans, and groundnuts had their highest CE of $95.09 \%, 87.61 \%$, and $81.67 \%$ at the inner sieve size of $13 \mathrm{~mm}, 16 \mathrm{~mm}$, and $10 \mathrm{~mm}$ respectively.

\section{Conclusions}

A Pedal operated seed-Cleaner (PoS-Cleaner) with a cleaning rate of 3-5 times higher than the conventional seed cleaning methods was designed, developed and the tested. This presents a better alternative compared to the trays, baskets and sieves that were associated with drudgery, dust exposure and postharvest losses as a result of inefficiencies. Therefore, continued promotion of this cleaner would result in to timely cleaning operations, quality produce, dust free environment and in the long run increase incomes.

Acknowledgements This study was funded by the Government of Uganda (GoU) through Makerere University Research and Innovation Fund (MaK-RIF). Special thanks to the entire technical team including; Sulaiman Buwembo \& Ibrahim Kamulegeya Flint at Badaye Technologies Ltd for their support, knowledge exchange and guidance during the design, construction and testing of the machine.

Funding This work was made possible by funds from the government of Uganda through Makerere University Research and Innovation Fund.

Declarations

Conflict of interest The authors declare that they have no conflict of interest.

Open Access This article is licensed under a Creative Commons Attribution 4.0 International License, which permits use, sharing, adaptation, distribution and reproduction in any medium or format, as long as you give appropriate credit to the original author(s) and the source, provide a link to the Creative Commons licence, and indicate if changes were made. The images or other third party material in this article are included in the article's Creative Commons licence, unless indicated otherwise in a credit line to the material. If material is not included in the article's Creative Commons licence and your intended use is not permitted by statutory regulation or exceeds the permitted use, you will need to obtain permission directly from the copyright holder. To view a copy of this licence, visit http://creativecommons. org/licenses/by/4.0/.

\section{References}

1. Carcea M (2020) Nutritional value of grain-based foods. Foods. https://doi.org/10.3390/foods 9040504 
2. McKevith B (2004) Nutritional aspects of cereals. Nutr Bull 29:111-142

3. Çakir Ö, Uçarli C, Tarhan Ç, Pekmez M, Turgut-Kara N (2019) Nutritional and health benefits of legumes and their distinctive genomic properties. Food Sci Technol 39(1):1-12. https:// doi.org/10.1590/fst.42117

4. UBOS (2010) Uganda Census of Agriculture 2008/2009. Uganda Bureau of Statistics, Kampala

5. Larochelle C, Katungi E, Cheng Z (2017) Pulse consumption and demand by different population subgroups in Uganda and Tanzania. https://core.ac.uk/download/pdf/132691721.pdf

6. FAO, WFP, and IFAD (2019) Food loss analysis: causes and solutions-The Republic of Uganda. Beans, maize, and sunflower studies. Food and Agricultural Organisation, Rome

7. Tibagonzeka JE, Akumu G, Kiyimba F, Atukwase A, Wambete J, Bbemba J, Muyonga JH (2018) Post-harvest handling practices and losses for legumes and starchy staples in Uganda. Agric Sci 9:141-156. https://doi.org/10.4236/as.2018.91011

8. Mayanja IK, Kigozi J, Kawongolo JB, Brumm TJ (2018) Design, fabrication and testing of a pedal operated maize grain cleaner. J Adv Food Sci Technol 5(3):105-111

9. Mishra A, Sinha JP, Singh JK, Tomar BS (2018) Development of solar powered pneumatic grain/seed cleaning system. Indian J Agric Sci 88(11):1676-1681

10. NPA (2013) Policy paper on transforming smallholder farmers farming to modern agriculture in Uganda. National Planning Authority, Kampala

11. Bellocq B, Ruiz T, Delaplace G, Duri A, Cuq B (2017) Screening efficiency and rolling effects of a rotating screen drum used to process wet soft agglomerates. J Food Eng 195:235-246. https:// doi.org/10.1016/j.jfoodeng.2016.09.023

12. Lee MD, Lee PS (2020) Design and development of size segregation sieve machine with centrifugal action. Univ J Mech Eng 8(4):208-215. https://doi.org/10.13189/ujme.2020.080406

13. Amoah JY, Aggey M, Addo D, Abdulai I (2017) Development and performance evaluation of a mechanized two ply palm nut cracked mixture rotary sieve. J Ghana Sci Assoc 17(2):47-51

14. Khurmi RS, Gupta JK (2005) A textbook of machine design, 1st edn. Eurasia Publishing House (Pvt.) Ltd, New Delhi

15. Sobowale SS, Adebiyi JA, Adebo OA (2015) Design, construction and performance evaluation of a melon seeds sheller. J Food Process Technol 6(7):1000463. https://doi.org/10.4172/21577110.1000463

16. Ojediran JO, Okonkwo CE, Okunola AA, Alake AS (2018) Development of a motorized rice de-stoning machine. Agric Eng Int CIGR J 20(4):202-209
17. Afolabi OA, Emeka OC, Gift OA, Faith A, Adeniyi OT (2019) Design, development and evaluation of a pneumatic cum eccentric drive grain cleaning machine: a response surface analysis. Asian J Sci Res 12(4):462-471. https://doi.org/10.3923/ ajsr.2019.462.471

18. Simonyan KJ, Yiljep YD (2008) Investigating grain separation and cleaning efficiency distribution of a conventional stationary rasp-bar sorghum thresher. Agric Eng Int CIGR EJ 10(Manuscript PM 07 028):1-13

19. Okunola AA, Igbeka JC, Arisoyin AG (2015) Development and evaluation of a cereal cleaner. J Multidiscip Eng Sci Technol 2(6):1587-1592

20. Yenge GB, Kad VP, Nalawade SM (2018) Physical properties of maize (Zea mays L.) grain. J Krishi Vigyan. https://doi.org/10. 5958/2349-4433.2018.00173.3

21. Abbiss CR, Peiffer JJ, Laursen PB (2009) Optimal cadence selection during cycling. Int SportMed J 10(1):1-15

22. Singh $Y$, Chandra S (2014) Evaluation of physical properties of kidney beans (Phaseolus vulgaris). Food Sci Res J 5(2):125-129. https://doi.org/10.15740/has/fsrj/5.2/125-129

23. Davies RM (2009) Some physical properties of groundnut grains. Res J Appl Sci Eng Technol 1(2):10-13

24. Soyoye BO, Ademosun OC, Agbetoye AS (2018) Determination of some physical and mechanical properties of soybean and maize in relation to planter design. Agric Eng Int: CIGR J 20(1):81-89

25. Bart-Plange A, Addo A, Aveyire J, Tutu E (2007) Friction coefficient of maize, cowpea and groundnuts on different structural surfaces. J Sci Technol 27(1):142-149

26. MAAIF (2018) Maize training manual for extension workers in Uganda. https://www.agriculture.go.ug/wp-content/uploa ds/2019/09/Maize-training-manual-for-extension-workers-inUganda.pdf

27. Finch-Savage WE, Bassel GW (2016) Seed vigour and crop establishment: extending performance beyond adaptation. J Exp Bot 67(3):567-591. https://doi.org/10.1093/jxb/erv490

Publisher's Note Springer Nature remains neutral with regard to jurisdictional claims in published maps and institutional affiliations. 